\title{
Performance analysis of supercapacitors for transportation industry
}

\author{
Vinoth Jonathan Nagarajah', Hui Jing Lee ${ }^{2}$, King Guan Tan ${ }^{3}$, Nathawat Khunprasit ${ }^{4}$ \\ ${ }^{1,2}$ Institute of Power Engineering (IPE), College of Engineering, Universiti Tenaga Nasional (UNITEN), Malaysia \\ ${ }^{3,4}$ SCOMI Rail Bhd, Jalan Monorail, Kg Sungai Choh, Selangor, Malaysia
}

\begin{tabular}{ll} 
Article Info & ABSTRACT \\
\cline { 3 - 3 } Article history: & $\begin{array}{l}\text { Monitoring device is essential to ensure a reliable and a healthy lifespan of } \\
\text { the energy storage system. Hence, a monitoring device is needed to monitor } \\
\text { the state of health and state of charge of a Supercapacitor. This project aims }\end{array}$ \\
Received Oct 5, 2018 & $\begin{array}{l}\text { to demonstrate a method to monitor Supercapacitors using a microcontroller } \\
\text { in both hardware and software approaches. The data was successfully } \\
\text { Accepted Dec 25, 2018 }\end{array}$ \\
\begin{tabular}{l} 
collected by an online platform called ThingSpeak. \\
\hline
\end{tabular}
\end{tabular}

Keywords:

IoT

Monitoring

State of charge

State of health

Supercapacitors

Copyright $@ 2019$ Institute of Advanced Engineering and Science. All rights reserved.

\section{Corresponding Author:}

Vinoth Jonathan Nagarajah,

Institute of Power Engineering (IPE),

College of Engineering, Universiti Tenaga Nasional (UNITEN),

43000 Kajang, Selangor, Malaysia.

Email: vinoth.jonathan@gmail.com

\section{INTRODUCTION}

Today, the use of electric vehicles has become more popular hence an efficient energy storage system (ESS) is required for energy storage to drive the electric motor. Supercapacitor (SC) is commonly used due to its high-power density, fast charging and discharging capability and relatively long-life cycle. SC was first patented at General Electric Corporation by Becker in 1957 where a low voltage electrolytic capacitor with porous carbon electrode was established [1]. An electrical energy storage of the SC was then established by scientists at Standard Oil of Ohio (SOHIO) in 1966 [2]. An electrolytic capacitor with activated carbon electrodes was then patented in 1970 by Donald L. Boos [3]. Panasonic then created SC of Goldcaps with strong energy source for memory backup applications in 1978 [4]. Later on, in 1987, company ELNA introduced the "Dynacap" capacitor which was the first generation on Electrical Double Layer Capacitor (EDLC) with a limited amount of discharge sue to its high internal resistance (IR) [5]. This has limited its application to a low current utilization such as supplying energy for a Static-Random Access Memory (SRAM) chip or for data backup purpose.

In 1980's, scientist discovered materials to increase the capacitance of a SC. Also, to reduce equivalent series resistance (ESR), scientists created electrolytes with better conductivity which will therefore increase the charge and discharge current [6]. In the same year, SC with low IR was used in the military applications by Pinnacle Research Institute (PRI) which is named as "PRI Ultra-capacitor" [7]. In 1992, Maxwell laboratories then rebranded "PRI Ultra-capacitor" to "Boost Caps". An Electrolytic-Hybrid Electrochemical Capacitor was created by David A [8]. In 1994, an anode of $200 \mathrm{~V}$ high voltage tantalum electrolytic capacitor was implemented hence the features of electrochemical capacitors and electrolytic capacitors were combined [9]. The invention of this feature is called the "Capattery" which it has five times 
the energy value of a comparable tantalum electrolytic capacitor [10]. The lithium-ion SC was led by FDK in 2007. They fuse an electrostatic carbon electrode with pre-doped lithium-ion electrochemical electrode [11]. This in return creates a higher capacitance value. Today, application of SCs is widely found in the transportation industry such as bus, trams system and the regenerative breaking in railway systems [12].

The purpose of balancing in SC is to prevent overvoltage during the charging process of SCs. Overvoltage will reduce the lifespan of SC or in the worst case it will lead to the destruction of SC. Types of SC balancing include passive balancing using resistors, active balancing with Buck-Boost based balancing, flyback converter balancing, multi-winding transformer (MWT) and multi-transformer shunting balancing (MTS) [13]. For passive balancing with resistor, one compromise that has to be made is the time required to balance SC versus the leakage current [14]. As for the Buck-Boost based active balancing, both overvoltage and undervoltage will be sensed and transferred to the adjacent cells. However, the circuit is big and requires an accurate voltage monitoring. Flyback converter balancing uses the pack to cell energy transfer. Monitoring of each SC is not required; to balance $n$ number of cells in series, n-number of diodes and $n+1$ coupled inductors are required. MWT makes balancing simpler as it does not require a voltage sensor. On the other hand, MTS involves several transformers hence the design would be costly [15].

To maintain the security and reliability of SCs, SCs should be monitored by a management system which include the hardware and software units. It is used for monitoring, state estimating and balancing. Temperature and voltage are measured to ensure that the elements do not exceed the maximum operating range, this is essential to ensure the safety of system and users. To prove the autonomy of the SC system, information about the state of charge (SOC) of the system is needed. To ensure that SC does not need early replacement, state of state of health $(\mathrm{SOH})$ is to be monitored in the system. Scanning capacitor microscopy (SCM) requires measured data such as voltages, current and temperature to estimate the state of the cell [16].

One way of monitoring SCs is by using a microcontroller connected to multiple sensors to gather different types of data [17]. By constructing a software to be uploaded to the microcontroller, this data can be used to generate the SOC and SOH of the SC. Arduino microcontroller is commonly used to monitor SCs. To aid the uploading process of programs to the on-chip flash memory, Arduinos are programmed with a boot loader called "Optiboot". A computer is used to load the program code into the Arduino via a serial connection. New models of Arduino are programmed using Universal Serial Bus (USB). Other types of Arduino such as Arduino Mini use a detachable USB to serial programmed using its individual in-circuit serial programming (ICSP) header. Hence, this paper presents on the monitoring result using an Arduino microcontroller. By using the Arduino board connected to external shields such as current shield, voltage shield, Ethernet shield, button and a relay, a monitoring system can be constructed to monitor the SOC and $\mathrm{SOH}$ of SCs. The monitoring system can utilize an internet of thing (IOT) based cloud data collection and storage system. Such implementation would be made applicable in the regenerative braking in transportation industry.

\section{MONITORING OF SUPERCAPCITOR}

This research work was undertaken to monitor the SOC and SOH of SCs with both hardware and software development. This combination will be able to monitor the SCs by using a microcontroller connected to multiple sensors. The data will then go through the software where the sensor's data will be interpreted and displayed on the serial monitor. Figure 1 shows the flowchart of the overall design of the system used to ease the flow of hardware programming.

The software used to program the Arduino Mega is an open source Arduino software. This workflow involves initialization, idle state, charging state, after charging state, discharging state, after discharging state, overvoltage state, data collection by MicroSD card and data collection on ThingSpeak. During the initialization process, the Arduino will verify if a MicroSD card is installed. This is to make sure all the data collected is recorded for security and reliability purposes. The idle state shows that SCs are waiting to be charged or discharged where both the current and voltage information will be displayed. The loop will run infinite times till it detects a charging current or discharging current.

When the Arduino detects a current of more than 0.9 A from the power source it will be in the charging state. After the SCs are charged and the Arduino detects that the current is less than $0.2 \mathrm{~A}$, it will be in the after charging state where it will display the health of each SC as well as using Equation 1 to calculate and display the time taken to charge the SCs. When the SCs are connected to a load and have a discharging current of more than $0.4 \mathrm{~A}$ it will be in the discharging state. During the discharging state, the estimate time to discharge the SC will be calculated and displayed using Equation 1. After the discharging is complete and the current sensor detects a current of less than $0.2 \mathrm{~A}$, it will be in the after discharging state where the Arduino will indicate that the discharging is complete. During every state, the voltage of each SC, voltage sum of all the SCs and current will be recorded and displayed. 


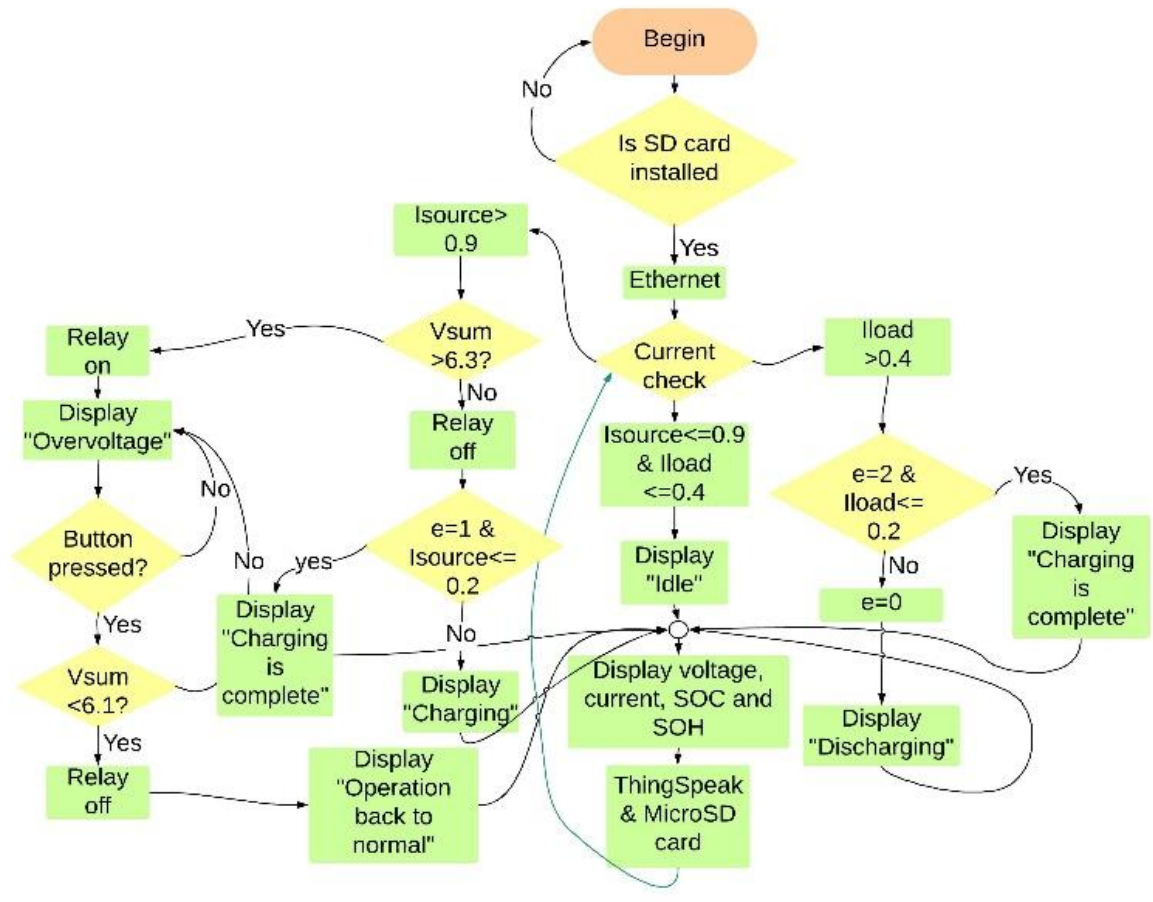

Figure 1. Work flow of overall system

The components consist of an Arduino Mega, current sensor shield, voltage sensor shield, Ethernet shield with MicroSD card slot and a Relay. Full circuit construction of the monitoring system prototype is shown in Figure 2 and Figure 3. The monitoring system consists of an Arduino Mega, Ethernet shield with SD card, four voltage sensors, two current sensors, relay, push button and a LED. Four voltage sensors are used to monitor voltage of each individual SC. Current sensors are used to monitor the charging and discharging current. A relay is connected to the power source and supercap1 to break the circuit if an overvoltage occurs. A red LED is used to indicate when an overvoltage occurs. Besides, a push button is used to reset the circuit after the overvoltage has been cleared to a lower voltage $(<6.1 \mathrm{~V})$.

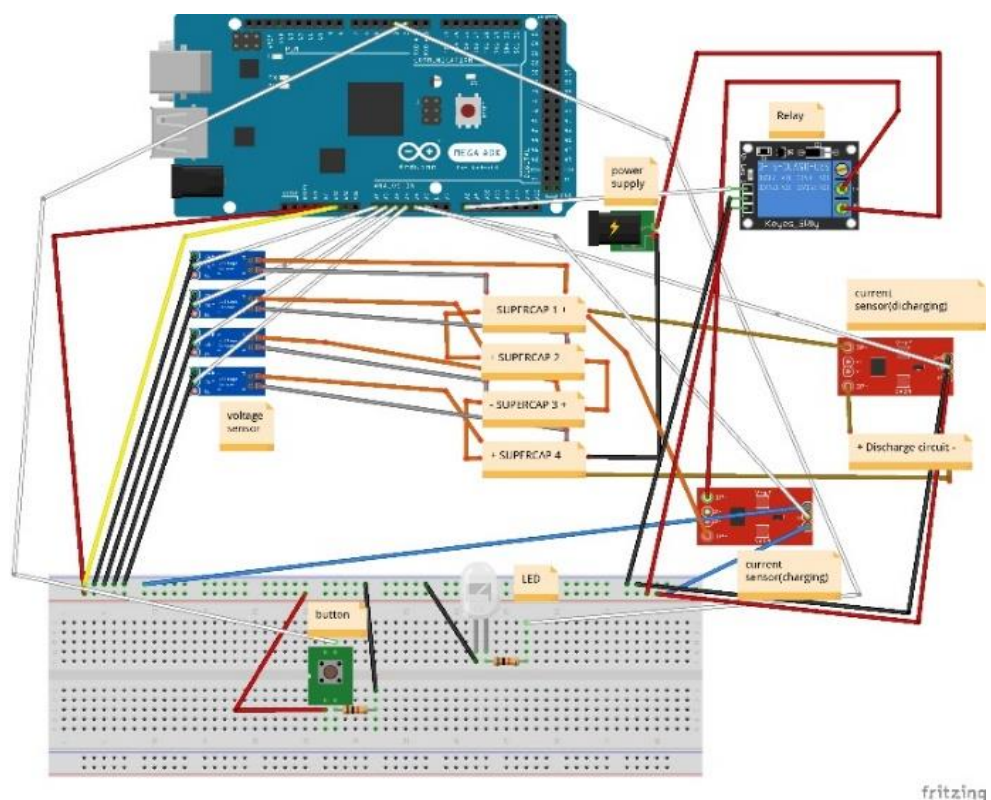

Figure 2. Prototype sketch 


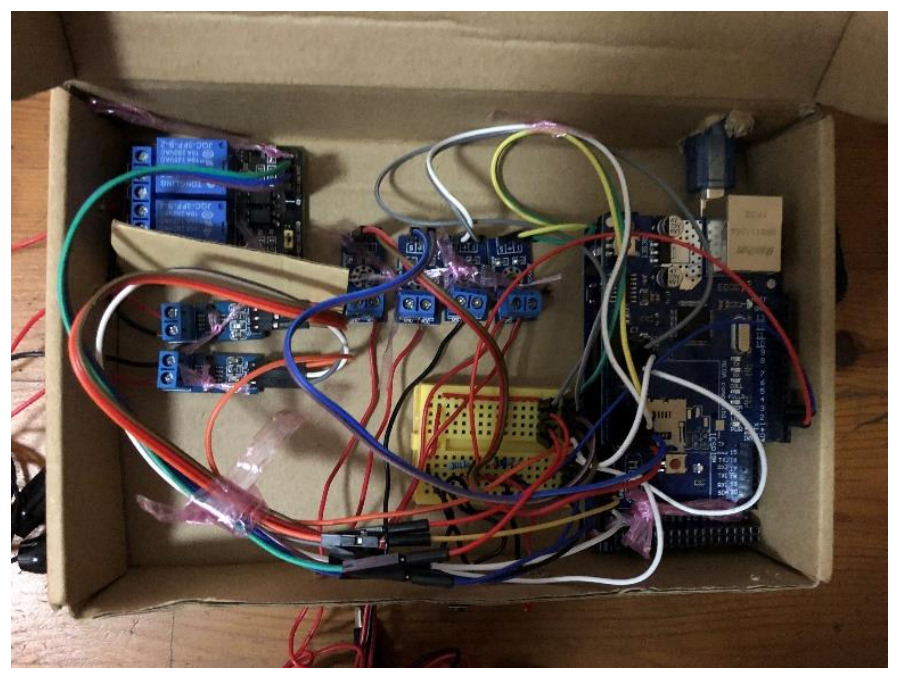

Figure 3. Design of full prototype

elapsedTime $=$ millis - startTime

To calculate the capacitance of each individual SC, Equation 2 is used. "Ccap" is the calculated capacitance, "I" is the current used to charge the SCs, "t2" is the value stored in variable "fullTime", "t1" is the value stored in variable "capTime", "V2" is the data stored in function called "voltageChange()" and "V1" is the data stored in function called "initialVoltage".After calculating the capacitance of each SC, Equation 3 is used to calculate the health of each SC. Rated capacitance is the rated capacitance given by the manufacturer. The " $\mathrm{e}$ " value will be set to zero.

$$
\begin{aligned}
& C_{\text {cap }}=\frac{I *\left(t_{2}-t_{1}\right)}{V_{2}-V_{1}} \\
& C_{\%}=100-\left(\left(\frac{\text { rated capacitance }-C_{c a p}}{\text { rated capacitance }}\right) \times 100\right)
\end{aligned}
$$

\section{RESULTS AND ANALYSIS}

The SCs were tested to verify that they have a capacitance value of $3200 \mathrm{~F}$. It is significant to identify and verify the initial value of capacitance as the monitoring process requires an accurate initial reading of the SCs. Next, sensors testing was conducted. Sensors testing was conducted to ensure accurate readings are measured by the sensor to be used in the monitoring system. Finally, results and findings from full prototype testing is presented.

To verify the capacitance of the SCs. A constant current source is used to charge the SCs to $2.5 \mathrm{~V}$ each. A multimeter was used in parallel to monitor the voltage change of the SCs. The constant current used was 3 A. Multiple experiments were carried out to get a more accurate reading. Table 1 shows the Final voltages (V) and Time Taken (minutes) after a constant current of 3 A was used to charge the SCs to $10 \mathrm{~V}$. Equation 1 is used to calculate total capacitance of the SCs. This formula was taken from the testing manual of Skeleton Technologies' Supercapacitor. Time taken (minutes) is converted to seconds to be used in equation as $t_{2}$. It is observed that the total measured capacitance in series is above $800 \mathrm{~F}$. This shows that the $3200 \mathrm{~F}$ SCs are healthy and are manufactured according to specification. Formula to calculate total capacitance in series is given in equation 4 .

$$
\mathrm{C}_{\text {total }}=\frac{1}{\frac{1}{\mathrm{C}_{1}}+\frac{1}{\mathrm{C}_{2}}+\cdots \frac{1}{\mathrm{C}_{\mathrm{n}}}}
$$

A voltage sensor shield was used to monitor individual voltages of the SCs. The voltages were monitored to prevent an overvoltage. Overvoltage causes a reduced lifespan on a SC. Table 1 shows the voltage sensor shield testing on a single SC and is validated using a multimeter. Percentage of error is calculated and recorded in the same table. Percentage of error is given by the formula in equation 4.3. As 
seen in Table 1, the percentage of error decreases as the voltage increases. The percentage of error does not go above $5 \%$ which is the maximum acceptable error for this project.

Table 1. Percentage Error For Voltage Sensor

\begin{tabular}{|c|c|c|c|}
\hline No & $\begin{array}{l}\text { Voltage Sensor } \\
\text { reading }(\mathrm{V})\end{array}$ & $\begin{array}{l}\text { Multimeter reading } \\
\text { (V) }\end{array}$ & $\begin{array}{c}\text { Percentage of } \\
\text { error }(\%)\end{array}$ \\
\hline 1 & 0.21 & 0.20 & 5.00 \\
\hline 2 & 1.05 & 1.20 & 4.20 \\
\hline 3 & 2.60 & 2.50 & 4.00 \\
\hline
\end{tabular}

In this research work, four SCs were charged to a sum of $6 \mathrm{~V}$. Voltage readings were then taken using a digital multimeter and four voltage sensors. An ACS 712 current sensor was used to monitor the current that flowed from the source to the SC during charging and monitor the current that flowed from the SC to the load during discharge. Experiment was done by charging four series connected 3200F SCs at different current values. Results from multiple tests were recorded in Table 2. It was observed that the percentage of error was less than $5 \%$. The percentage of error of the current sensor was $2.9 \%$. This value can be obtained by using equation 4 .

$$
\% \text { error }=\left|\frac{\text { multimeter reading-sensor reading }}{\text { multimeter reading }}\right| \times 100 \%
$$

Table 2. Percentage Error For Current Sensor

\begin{tabular}{llcc}
\hline No & $\begin{array}{c}\text { Current Sensor } \\
\text { reading (A) }\end{array}$ & $\begin{array}{c}\text { Multimeter reading } \\
(\mathrm{A})\end{array}$ & $\begin{array}{c}\text { Percentage of } \\
\text { error }(\%)\end{array}$ \\
\hline 1 & 1.03 & 1.00 & 3.00 \\
2 & 2.07 & 2.00 & 3.30 \\
3 & 3.09 & 3.00 & 2.90 \\
\hline
\end{tabular}

Monitoring states of the full prototype testing involve: idle state, charging state, after charging state, discharging state, and overvoltage state. The experiments conducted are charged at a constant current of 3A till a maximum overvoltage state of $6.3 \mathrm{~V}$. A $1.1 \Omega, 10 \mathrm{~W}$ resistor is used to discharge the SCs till $400 \mathrm{mV}$. Figure 4 to Figure 7 show the live voltage readings of each SC while Figure 8 shows the voltage sum of all the SCs. The charging and discharging currents are shown in Figure 9 and Figure 10. In Figure 11, if relay status shows " 1 ", this is to indicate that the relay has been tripped and an overvoltage has occurred while " 0 " indicates that the relay is closed and the circuit is operating normally. Voltage graph for second SC as shown in Figure 5 and Voltage graph for third SC as shown in Figure 6.

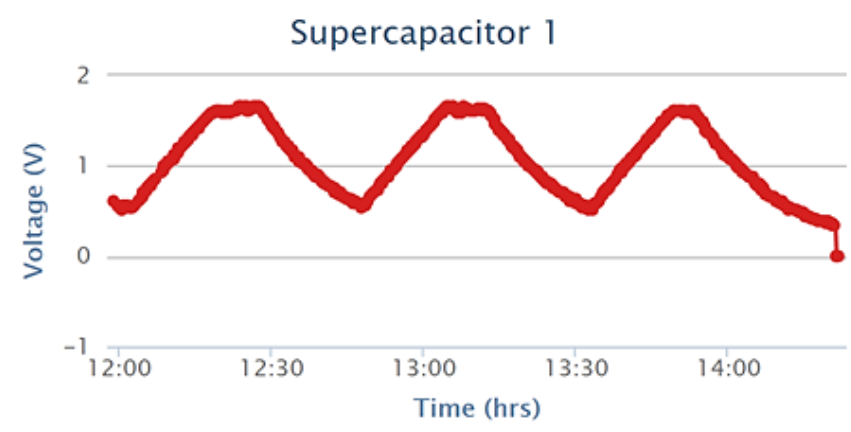

Figure 4. Voltage graph for first SC 


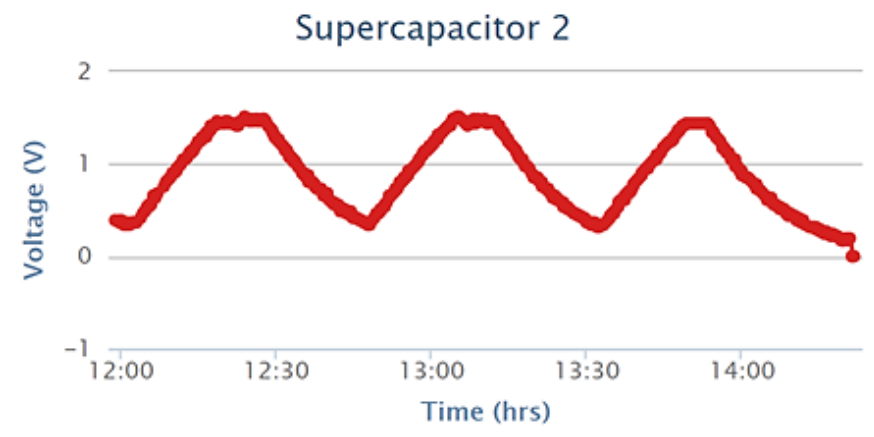

Figure 5. Voltage graph for second SC

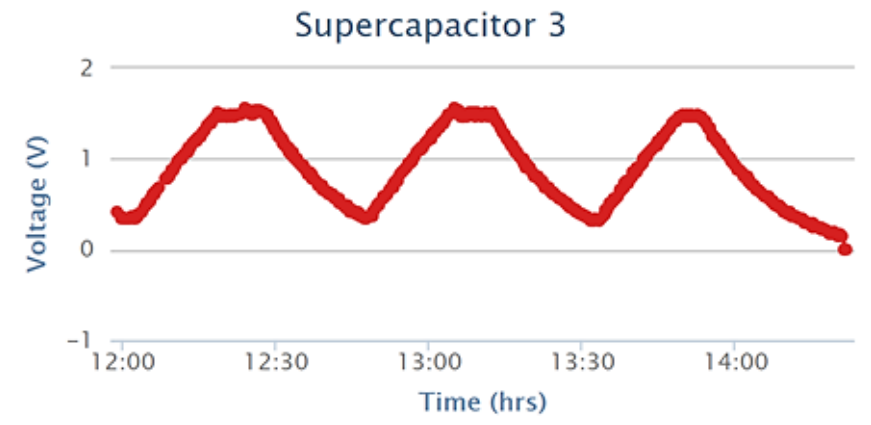

Figure 6. Voltage graph for third SC

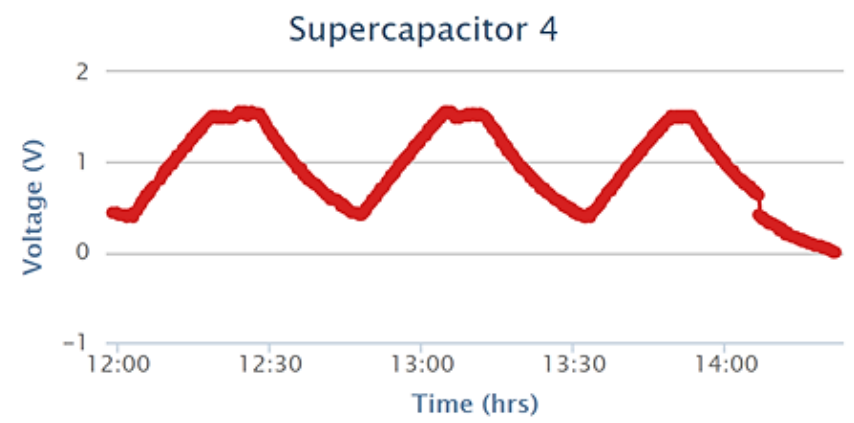

Figure 7. Voltage graph for fourth SC

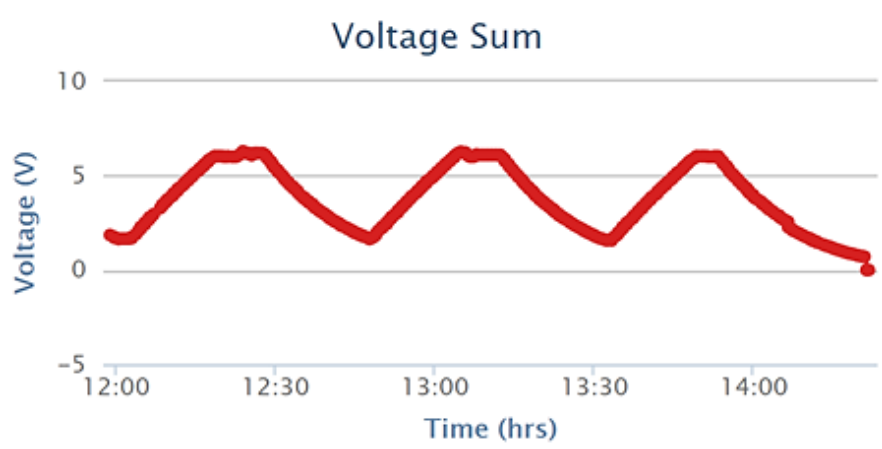

Figure 8. Voltage graph for sum of four SC's voltage 


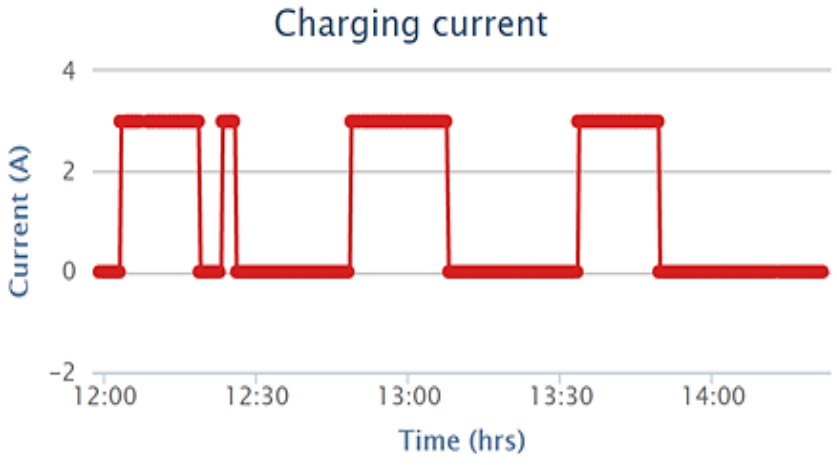

Figure 9. Charging current graph

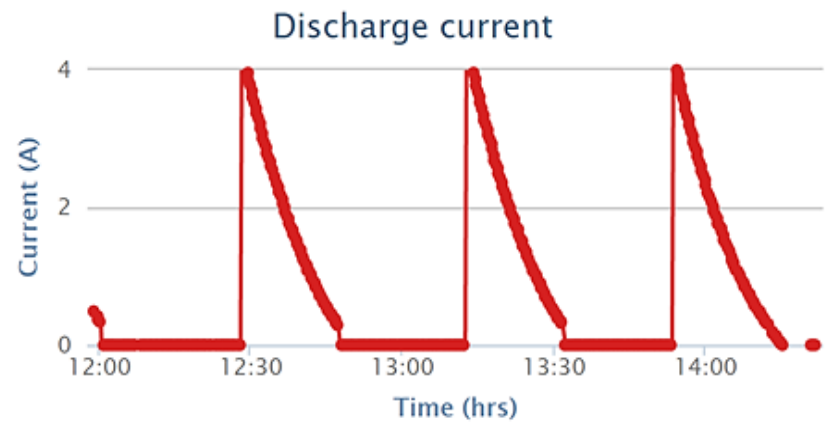

Figure 10. Discharging current graph

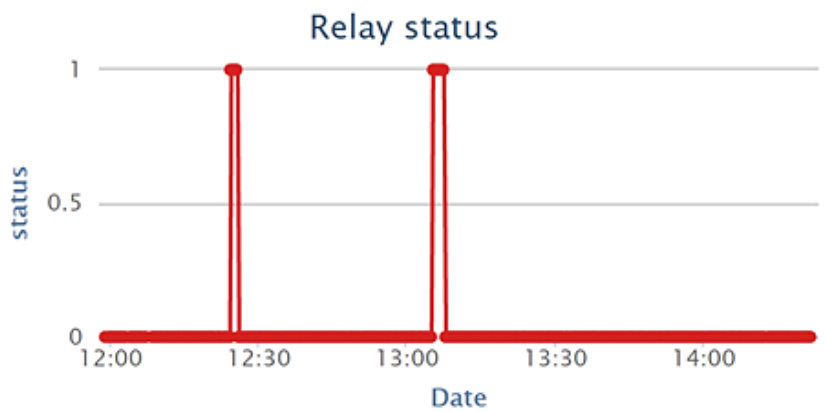

Figure 11. Relay status

\section{CONCLUSION}

This paper monitors the state of charge and state of health of supercapacitor using an Arduino Mega microcontroller. The sensors consisted of four voltage sensors and two current sensors. Arduino Mega processed the data collected from the sensor and able to produce an accurate state of charge and state of health of the supercapacitors. The monitoring system is hence able to prevent the overcharging of supercapacitor. This will ensure that the supercapacitor operates at a full lifespan. The data was collected by an online platform called ThingSpeak which enabled the end user to view the state of charge and state of health of supercapacitors in live data.

\section{ACKNOWLEDGEMENTS}

We thank Universiti Tenaga Nasional internal grant RJO10289176 for the support. 


\section{REFERENCES}

[1] H. I. Becker. "Low voltage electrolytic capacitor," United States Patent US2800616A, 1957.

[2] R. A. Rightmire, "Electrical energy storage apparatus," US Patent 3288641, 1966.

[3] Conway, Brian Evans. "Transition from 'Supercapacitor' to 'Battery' Behavior in Electrochemical Energy Storage" May 1991, J. Electrochem. Soc. 138, vol 6, pp 1539-1548.

[4] Conway, Brian Evans. "Electrochemical Supercapacitors: Scientific Fundamentals and Technological Applications" 1999. Berlin, Springer. pp. 1-8.

[5] F. Elzbieta, Béguin Francois. "Carbon materials for the electrochemical storage of energy in capacitors" May 2001, Carbon, Vol 39 (6), pp. 937-950.

[6] L. Despotuli, A.V Andreeva. "Advanced Carbon Nanostructures" for "Advanced Supercapacitors: What Does it Mean?" February 2011. Nanoscience and Nanotechnology, Vol 3, pp 119-124.

[7] G. L. Yu, R. Jalil, B. Belle, A. S. Mayorov. "Interaction phenomena in graphene seen through quantum capacitance" February 2013 PNAS vol 110, pp 3282-3286.

[8] F. Elzbieta, K. Jurewicz, K. Delpeux, B. Francois."Nanotubular Materials for Supercapacitors"July 2011, J. Power Sources, vol 97-98, pp 822-825.

[9] V. L. Pushparaj, M. M. Shaijumon, A. Kumar, S. Murugesan. "Flexible energy storage devices based on nanocomposite paper" August 2007, Proc. Natl. Acad, Sci. USA vol 104 pp. 13574-13577.

[10] M. F. El-Kady, V. Strong, S. Dubin, R.B. Kaner. "Laser scribing of high-performance and flexible graphene-based electrochemical capacitors" March 2015, Science, vol 335, pp. 1326-1330.

[11] N. Sidhu, L. Patnaik and S. S. Williamson, "Power electronic converters for ultracapacitor cell balancing and power management: A comprehensive review," IECON 2016 - 42nd Annual Conference of the IEEE Industrial Electronics Society, Florence, 2016, pp. 4441-4446.

[12] F. Ibanez, J. Vadillo, J. M. Echeverria and L. Fontan, "Design methodology of a balancing network for supercapacitors," IEEE PES ISGT Europe 2013, Lyngby, 2013, pp. 1-5.

[13] W. Jiang, X. Wu, R. Hu and W. Chen, "Balanced supercapacitor energy storage module based on multifunctional ISOS converter," 2014 IEEE Energy Conversion Congress and Exposition (ECCE), Pittsburgh, PA, 2014, pp. 2544-2549.

[14] S. Shili, A. Hijazi, A. Sari, P. Bevilacqua, P. Venet. "Online supercapacitor health monitoring using a balancing circuit" July 2016, Journal of Energy Storage, vol 7, pp. 159-166.

[15] N. Scharich, B. Schniter, A. Herbert and M. S. Islam, "Battery management system using Arduino," 2017 IEEE Technology \& Engineering Management Conference (TEMSCON), Santa Clara, CA, 2017, pp. 384-387.

[16] G. Barbon, M. Margolis, F. Palumbo, F. Raimondi, N. Weldin. "Taking Arduino to the Internet of Things: The ASIP programming model” March 2016, Computer Communications, vol 89-90, pp. 128-140.

[17] Sheikh Ferdoush, Xinrong Li,"Wireless Sensor Network System Design Using Raspberry Pi and Arduino for Environmental Monitoring Applications” 2014, Procedia Computer Science, vol 34, pp. 103-110. 